\title{
GENETIC POPULATION STRUCTURE IN POLYGYNOUS FORMICA ANTS
}

\author{
PEKKA PAMILO \\ Department of Genetics, University of Helsinki, P. Rautatiekatu 13, \\ SF-00100 Helsinki 10, Finland
}

Received 24.vi.81

\begin{abstract}
SUMMARY
Genetic population structures, both mating and interaction structures, were investigated in three polygynous Formica ants by examining how genotype frequencies are distributed among the nests in their populations. The study is based on electrophoretically analysed enzyme polymorphisms. The patterns of genotypic variation among single-nest workers suggest that polygyny is functional in all the three species. The observed genotype frequencies indicate outbreeding within the study areas, and no spatial microdifferentiation in gene frequencies is detected. The coexistent gynes in nests of both $F$. transkaucasica and $F$. polyctena are genetically related to each other, and the same holds for worker nest mates. These results support the hypothesis that polygyny is favoured by kin selection. The lack of genetic relatedness among gyne nest mates in the highly polygynous $F$. aquilonia suggests that additional factors, such as mutualism or parental parasitism, are probably involved in the evolution of polygyny.
\end{abstract}

\section{INTRODUCTION}

POLYGYNY, the existence of many egg-laying females (gynes) in a single nest, is rather a common phenomenon in ants. Of the European ant species about one half are classified as polygynous (Buschinger, 1974). It is known in social wasps and bees that, although the total productivity of a nest may increase, productivity per gyne decreases in multigyne associations (Richards and Richards, 1951; Michener, 1964). Similarly, in Formica ants the rate of egg-laying per individual is smallest in polygynous species (Gösswald, 1941; Schmidt, 1972). An apparent reduction of offspring numbers in multigyne associations has frequently led people to consider nests as superorganisms and to explain the evolution of polygyny through selection at the level of colonies or populations (Sturtevant, 1938; Oster and Wilson, 1978; see Crozier, 1979 for a review).

Lin and Michener (1972) have suggested that multiple foundress associations in wasps may be selected for because of beneficial mutual relationships. Mutualism could also serve as an explanation for pleometrotic nest founding in ants, but pleometrosis (= cooperative nest founding by several females) is not known to lead to permanent polygyny in ants (Hölldobler and Wilson, 1977). Another approach has been offered by Elmes (1973), who specially considered the relationships between gynes and workers. His observations in Myrmica ants support the view that the gynes can be considered as parasites on the colonies that readopt them.

Although polygyny could be favoured by mutualistic relationships, or maintained by parental parasitism, its evolution is also affected by trait group selection due to population subdivision. A population of polygynous 
nests can be considered a structured deme (see Wilson, 1980), in which genetically determined social traits may increase in frequency due to gene frequency variance between the nests. If the coexistent gynes are related to each other, the between-nest variance is greater and the conditions for such trait group selection are more favourable.

Genetic aspects of the evolution of polygyny were underlined by Craig and Crozier (1979), who discussed the problem in the light of Hamilton's $(1964 a, b)$ theory of social evolution by kinship associations. In another recent article, Hölldobler and Wilson (1977) stressed the ecological constraints on the evolution of polygyny. They suggested that polygyny in ants is either associated with short-lived nest sites or with stable but patchily distributed habitats. It is reasonable to assume that the evolution and maintenance of polygyny in ants is connected both with the genetic structure of the populations and the ecological circumstances.

The aim of the present study is to examine genetic population structures in three polygynous Formica ants (Hymenoptera, Formicidae). One of them, $F$. transkaucasica Nasonov ( $=F$. picea Nyl.), is a typical habitat specialist in the classification of Hölldobler and Wilson (1977). It inhabits bogs, the nests being located in the peat. The other two species, $F$. aquilonia Yarrow and $F$. polyctena Foerst., can also be classified as habitat specialists but, at least in northern Europe, their habitat is not patchily distributed. Both species form large polydomous societies (associations of cooperating nests) in coniferous and mixed forests (such habitats may have been patchy during the last ice age). The species build mound nests of needles and small twigs and the mounds have well-organized systems of foraging routes $(e . g$., Rosengren, 1971). The two species are highly polygynous, and the number of single-nest gynes may be up to tens or hundreds. In the present study, the population structures of the three species are examined by means of enzyme marker genes.

\section{MATERIAL AND METHODS}

\section{(i) Material}

The data on $F$. transkaucasica come from a population at Siikajärvi, Vihti, southern Finland. The population inhabits an open bog with a total area of about 20 ha. The nests are mainly located at the peripheral areas of the bog, and the material for the present study was collected from 55 nests within an area of $25 \mathrm{~m} \times 25 \mathrm{~m}$, which also included two small ponds (fig. 1). The nests were excavated in order to find the gynes. During the first sampling $(15, \mathrm{~V}, 1980)$, the bog was still frozen from a depth of $10 \mathrm{~cm}$ downwards, and during the second sampling (22, V, 1980), from $20 \mathrm{~cm}$ downwards. The ants were aggregated in the peat above the ice and the gynes were easy to find. The third sampling was done on 8, VI, 1980 when the ants were already active and dispersed so that it was difficult to detect the gynes. Most of the nests excavated contained eggs, which indicates that they were not mere wintering shelters but real summer nests (see Rosengren, 1969, for a discussion of winter and summer nests in another bog ant, Formica uralensis).

$F$. aquilonia and $F$. polyctena gynes were collected in late April and early May 1979, when they could be found in the upper parts of the mound, 


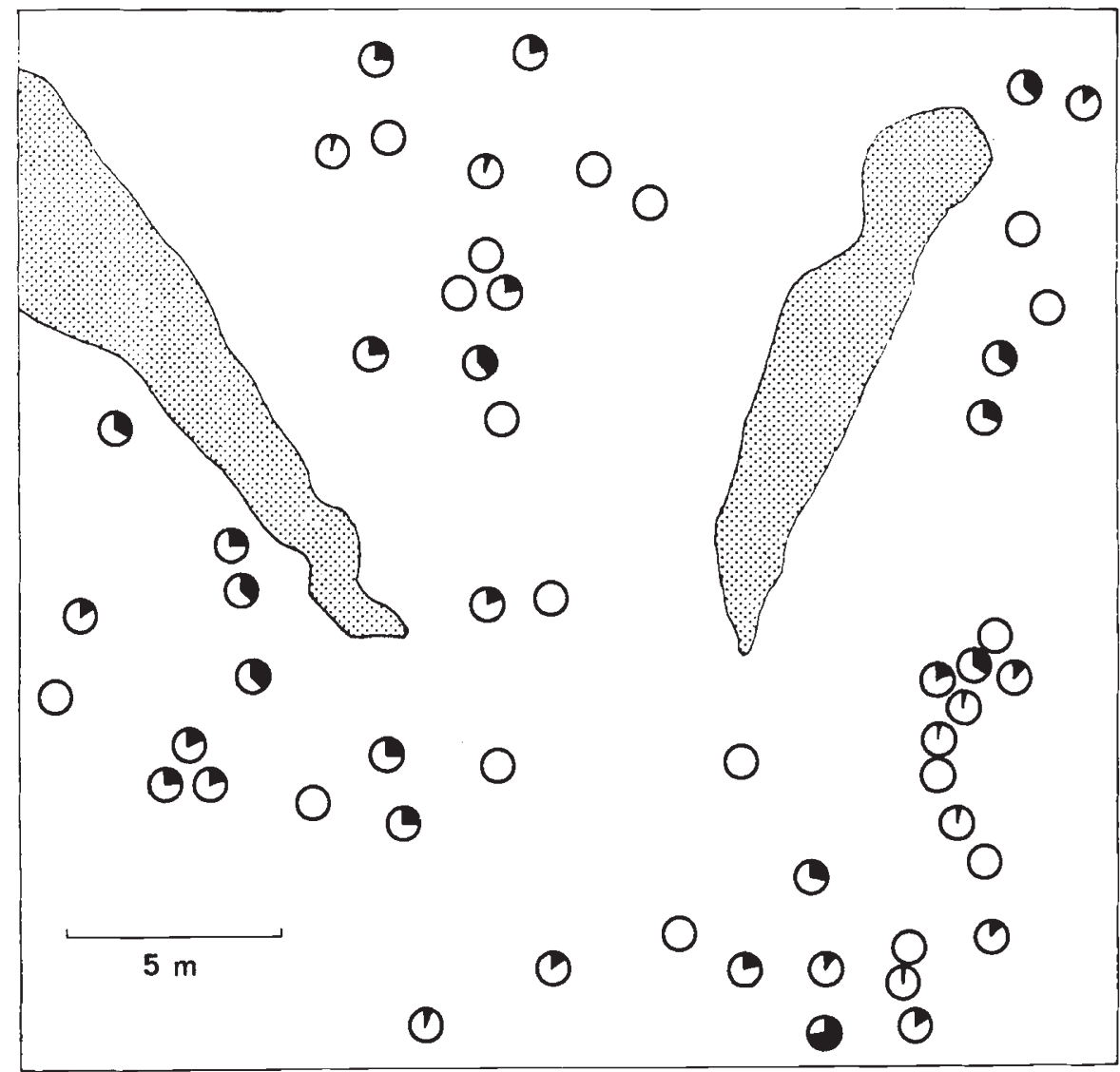

FIG. 1.-Allele frequencies among workers in the nests of Formica transkaucasica. The dark sector gives the frequency of the $\mathrm{S}$ allele and the light sector that of the $\mathrm{F}$ allele.

or on the mound surface. Two populations of each species were examined. The Espoo population of $F$. aquilonia at Solkulla was examined within an area of 6.5 ha (altogether 80 nests), and the Vantaa population at Keimola within an area of 5 ha ( 8 nests). The $F$. polyctena material came from 10 nests within 5 ha in Kauniainen and 18 nests within 30 ha in Siuntio.

Genetic variation was examined by horizontal starch gel electrophoresis (Pamilo et al., 1978), using the buffer system of Varvio-Aho and Pamilo (1980). In $F$. transkaucasica two polymorphic enzymes, malate dehydrogenase $(M d h)$ and esterase (Est), were detected. The latter could not be scored from workers. In $F$. aquilonia and $F$. polyctena, phosphoglucoseisomerase $(P g i)$ was found to be polymorphic. The genetic basis of the electrophoretic variation observed was confirmed by studying haploid males. While the workers and gynes showed a certain proportion of heterozygotes, the males always had a one-banded staining pattern as did the diploid homozygotes. The Pgi heterozygotes often showed just a broad band, but in successful stainings a three-banded pattern could be seen. In F. transkaucasica, a clear three-banded pattern was detected in the $M d h$ heterozygotes, whereas the heterozygotes for Est showed only two bands. 


\section{(ii) Statistical procedures}

Mating structure is analysed by calculating the deviation from the genotype frequencies expected in a panmictic population by a fixation index

$$
F=1-H_{\mathrm{o}} / H_{\mathrm{e}},
$$

where $H_{\mathrm{o}}$ is the observed heterozygosity and $H_{\mathrm{e}}$ that expected from $H_{\mathrm{e}}=$ $1-\sum x_{i}^{2} x_{i}$ denoting the frequency of the allele $i$. The deviation between the observed and expected genotype frequencies can be tested by $\chi^{2}=N F^{2}$ with one degree of freedom ( $\mathrm{Li}$ and Horvitz, 1953). The statistic is maximized $\left(\chi_{\max }^{2}\right)$ when $N$ is the total number of individuals examined. When the nest mates are genetically related to each other, they include redundant information and represent a number of independent individuals smaller than $N$.

Interaction structure measures inter-nest differentiation, i.e., how closely the nest mates are related genetically to each other with reference to the population average (see Wade, 1980; Pamilo and Crozier, 1981). A general measure of differentiation in subdivided populations is the standardized variance of the gene frequency (Wright, 1943)

$$
F_{\mathrm{ST}}=\frac{s_{x}^{2}}{\bar{x}(1-\bar{x})},
$$

where $s_{x}^{2}$ is the variance of the allele frequency among the nests and $\bar{x}$ is the mean frequency in the population.

The within-group genetic relatedness, $b$, can be defined as the average proportion of identical genes shared by two group members. Hamilton (1972, see also Michod and Hamilton, 1980) suggested that $b=$ $2 F_{\mathrm{ST}} /(1+F)$, where $F_{\mathrm{ST}}$ is calculated from (2) and $F$ from (1). When using small sample sizes, the estimate should include a sample size correction (Pamilo and Crozier, 1981). I used two methods to estimate genetic relatedness among nest mates: an intraclass regression coefficient (Pamilo and Crozier, 1981; see also Craig and Crozier, 1979) and an analysis of variance intraclass correlation coefficient (e.g., Cockerham, 1973; Donner and Koval, 1980). The coefficients take into account the sample size correction, and they are calculated from genotypic values, letting the electrophoretic genotypes have values 1 for $F F, 0.5$ for $F S$ and 0 for $S S$ ( $F$ and $S$ refer to the alleles representing fast and slow migrating allozymes). The standard error of the regression estimate is calculated according to standard methods, although this yields conservative confidence limits especially when $b$ is close to zero (Pamilo and Crozier, 1981). The significance of the difference of $b$ from zero is tested with a randomization test by rearranging the observed genotype numbers randomly in groups according to the sample sizes used. The observed estimate is then compared to the distribution of 1000 randomly generated values.

The estimates from (1) and (2) and the regression estimate of relatedness are calculated by weighting the nests equally and the estimates must be understood as average values per nest.

Spatial patterns of genetic differentiation within local populations are analysed in three alternative ways. Association of neighbour nests is examined by internest relatedness between nearest neighbours by applying 
the regression method (see Pamilo and Varvio-Aho, 1979 for the application of the method in between-group calculations). Differentiation within the whole area is further studied by regressing the genetic difference between the nests on the metric distance between them. Finally, the pattern of spatial variation in allozyme frequencies is tested for departure from randomness using the method of Royaltey et al. (1975). The method is based on a so called Gabriel connected graph joining the adjacent nests to each other, and the nests are given rank numbers according to their allele frequencies. The spatial pattern is now studied on the basis of the rank differences between interconnected nests (called the edge lengths of the graph). The observed mean edge length is compared to that expected in a random association of nests by a $t$ test, and the distribution of the edge lengths is compared to a random distribution by a $\boldsymbol{G}$ test.

\section{RESUlts}

\section{(i) Formica transkaucasica}

Altogether 159 gynes were found from 35 nests, the greatest number in a single nest being 27 , the arithmetic mean 4.5 and the harmonic mean $1 \cdot 8$ (table 1 , the gyneless samples are omitted from these values). Although several gynes probably managed to escape, it seems plausible that a gyne

TABLE 1

Numbers of various genotypes in the nests of F. transkaucasica in the Siikajärvi population

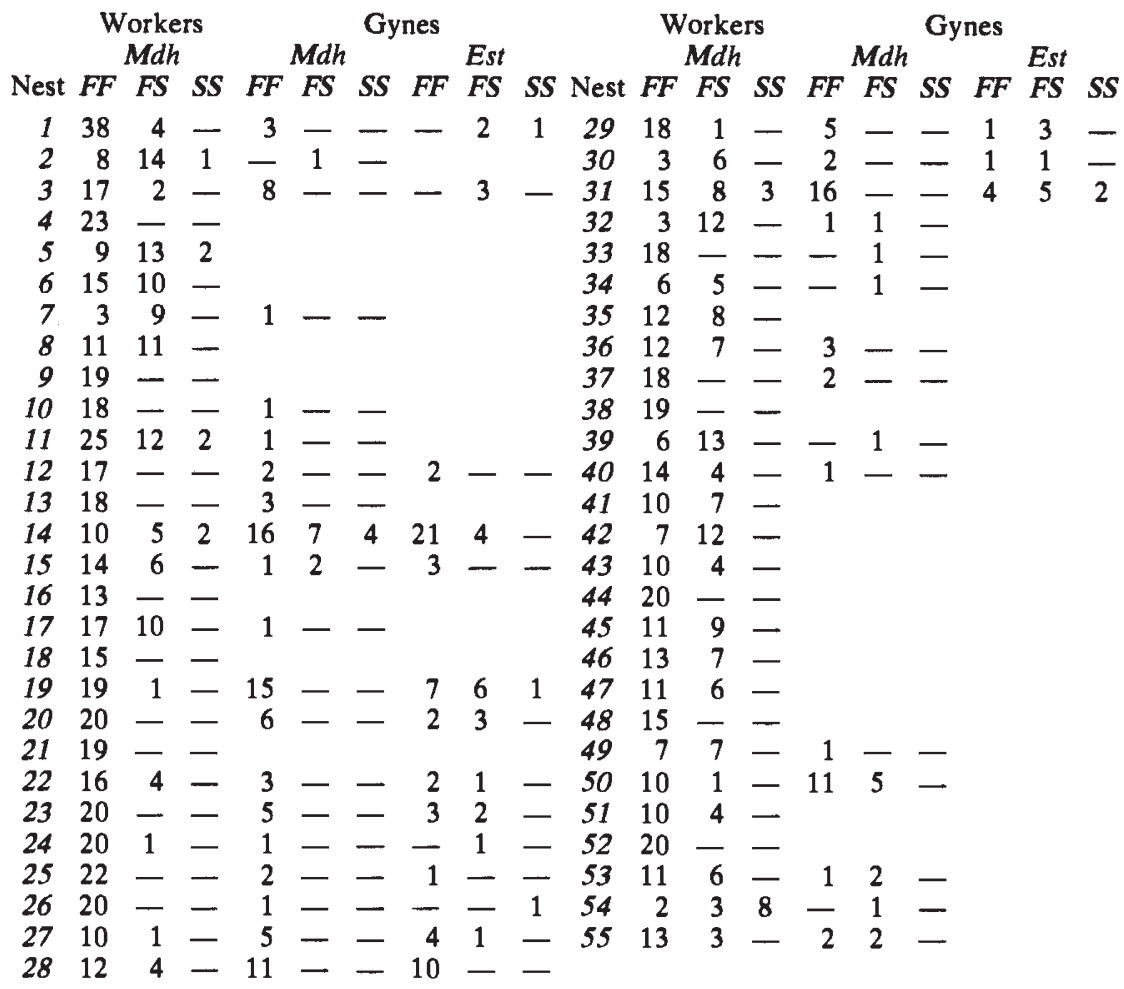


number exceeding ten per nest is not very common. The distribution of the gynes in the gyneright nests (table 1 ) fits a discrete log-normal distribution, with zero term truncated $\left(\chi_{(2)}^{2}=2 \cdot 91,0 \cdot 30>P>0 \cdot 20\right)$. All the gynes detected were inseminated, having sperm in the spermatheca.

Three alleles were found segregating at the $M d h$ locus. One of them was detected only in a single heterozygous gyne, its frequency being 0.003 (in all calculations requiring biallelic data this allele is combined with the $S$ allele). The two common alleles had frequencies 0.88 (the $F$ allele) and 0.12 (the $S$ allele) in the gynes. Esterases were assayed in only 98 gynes, the two alleles segregated with frequencies 0.72 and 0.28 . From these allele frequencies we obtain the expected heterozygosities 0.21 at $M d h$ and 0.41 at Est. The deviations from the observed heterozygosities, 0.23 and 0.38 , yield fixation indices $F=-0.093$ and 0.062 , respectively. The deviations are not statistically significant $\left(\chi_{\max }^{2}=1.38\right.$ and 0.38$)$.

1040 individual workers were sampled from 55 nests. On the basis of worker genotypes at $M d h$, there were 18 single-genotype nests, 31 twogenotype nests and 6 nests with three genotypes (table 1). The frequencies of the $F$ and $S$ alleles were 0.86 and 0.14 , giving an expected heterozygosity $H_{\mathrm{e}}=0 \cdot 24$, which exactly equals the observed one, so that $F=0$.

In gynes, the standardized allele frequency variance is $F_{\mathrm{ST}}=0.24$ for $M d h$ and 0.22 for Est, indicating that about 77 per cent of the total genic variation within the population can be found within single nests and 23 per cent is due to internest variation. The $F_{\mathrm{ST}}$ coefficient overestimates genic correlation by a factor inversely related to the sample size (see Pamilo and Crozier, 1981). The mean estimate of genetic relatedness among coexistent gynes (mean over $M d h$ and $E s t$ ) is $\bar{b}=0.26$ (table 2), the correlation method giving the estimate $0 \cdot 23$. The randomization test suggests that at both loci the relatedness estimate is significantly different from zero $(P=0.03$ and 0.01$)$.

The positive affinity of nest mates is also seen in workers. The mean estimates of genetic affinities in the 55 nests sampled are $F_{\mathrm{ST}}=0.19$ and $b=0.33 \pm 0.07$ (mean $\pm \mathrm{SE}$ ). Taking the same set of nests used for estimating the genetic relatedness among gynes, a value $b=0 \cdot 24 \pm 0 \cdot 11$ is obtained.

TABLE 2

Interaction structures given as estimates of genetic affinity of nest mates

\begin{tabular}{|c|c|c|c|}
\hline \multicolumn{2}{|c|}{ 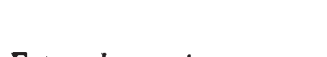 } & $F_{\mathrm{ST}}$ & $b \pm \mathrm{SE}$ \\
\hline \multicolumn{4}{|c|}{ F. transkaucasica } \\
\hline \multirow[t]{2}{*}{ Gynes } & $M d h$ & 0.24 & $0 \cdot 24 \pm 0 \cdot 16$ \\
\hline & Est & $0 \cdot 22$ & $0.29 \pm 0.20$ \\
\hline Workers & $M d h$ & $0 \cdot 19$ & $0.33 \pm 0.07$ \\
\hline \multicolumn{4}{|c|}{ F. aquilonia/Espoo } \\
\hline Gynes & $P g i$ & 0.08 & $0.01 \pm 0.11$ \\
\hline Workers & $P g i$ & 0.08 & $0.09 \pm 0.09$ \\
\hline \multicolumn{4}{|c|}{ F. aquilonia/Vantaa } \\
\hline Gynes & $P g i$ & 0.05 & $-0.02 \pm 0.14$ \\
\hline \multicolumn{4}{|c|}{ F. polyctena/Siuntio } \\
\hline Gynes & $P g i$ & $0 \cdot 35$ & $0.45 \pm 0.18$ \\
\hline Workers & $P g i$ & $0 \cdot 25$ & $0.29 \pm 0.15$ \\
\hline \multicolumn{4}{|c|}{ F. polyctena/Kauniainen } \\
\hline Gynes & $P g i$ & $0 \cdot 21$ & $0.19 \pm 0.34$ \\
\hline Workers & $P g i$ & $0 \cdot 27$ & $0.30 \pm 0.23$ \\
\hline
\end{tabular}


No genetic microdifferentiation is evident within the study area (fig. 1). Genetic relatedness between neighbouring nests, calculated as a regression coefficient $b=0.002 \pm 0.087$, reveals no affinity between the adjacent nests. Neither do the geographic distance and the pairwise allele frequency difference show any significant dependence (the regression coefficient of 0.003 is non-significant). Studying the geographic continuity reveals no significant departure between the observed and expected mean edge length in a Gabriel connected graph $(t=0.03, \mathrm{df}=\infty, \mathrm{ns})$. Nor does the distribution of the edge lengths depart from that expected on the basis of random differentiation $(G=7 \cdot 21$, $\mathrm{df}=9$, ns $)$.

\section{(ii) Formica aquilonia}

In the Espoo population, 168 gynes from 18 nests, and 296 workers from 21 nests were electrophoresed. The gynes assayed represent only a sample of the colony gynes. Of the 105 gynes dissected, 90 ( 86 per cent) had sperm in the spermatheca, being thus able to lay diploid eggs. The observations of R. Rosengren (personal communication) concur with this; he found 55 inseminated gynes out of 64 examined ( 86 per cent).

Two alleles were found segregating at the Pgi locus. The observed allele frequencies were 0.73 (the $F$ allele) and 0.27 (the $S$ allele) among the gynes, and 0.82 and 0.18 among the workers. The expected heterozygosities in gynes and workers are 0.39 and 0.29 , respectively. The observed heterozygosities 0.34 and 0.31 (table 3 ) thus give fixation indices $F=0.12$

TABLE 3

Numbers of the Pgi genotypes in the nests of F. aquilonia

\begin{tabular}{|c|c|c|c|c|c|c|c|c|c|}
\hline \multirow[b]{2}{*}{ Nest } & \multicolumn{4}{|c|}{ Gynes } & & & \multicolumn{3}{|c|}{ Workers } \\
\hline & & $F F$ & $F S$ & SS & Nest & & $F F$ & $F S$ & SS \\
\hline \multirow{18}{*}{ Espoo } & 1 & 10 & 4 & 2 & Espoo & 4 & 11 & 7 & - \\
\hline & 2 & 3 & 2 & - & & 5 & 9 & 6 & - \\
\hline & 3 & 17 & 5 & 2 & & 14 & 8 & 3 & - \\
\hline & 4 & - & - & 2 & & 20 & 9 & 4 & - \\
\hline & 5 & 3 & 2 & 1 & & 24 & 7 & 8 & 1 \\
\hline & 6 & - & 3 & - & & 27 & 7 & 5 & - \\
\hline & 7 & 4 & - & - & & 28 & 12 & 3 & - \\
\hline & 8 & 5 & 4 & - & & 30 & 3 & 6 & 1 \\
\hline & 9 & 3 & 1 & - & & 32 & 6 & - & - \\
\hline & 10 & 4 & - & - & & 34 & 14 & 3 & - \\
\hline & 12 & 1 & 1 & - & & 38 & 13 & 6 & - \\
\hline & 13 & 17 & 3 & - & & 39 & 14 & 1 & 1 \\
\hline & 14 & - & 1 & - & & 45 & 14 & 5 & - \\
\hline & 15 & 22 & 10 & 3 & & 46 & 6 & 9 & 4 \\
\hline & 16 & 6 & - & 1 & & 55 & 11 & 2 & - \\
\hline & 22 & 9 & 7 & - & & 57 & 11 & 3 & - \\
\hline & 23 & 4 & 6 & - & & 62 & 8 & 2 & - \\
\hline & & & & & & 63 & 11 & 4 & 1 \\
\hline \multirow[t]{3}{*}{ Vantaa } & 1 & 3 & 2 & 9 & & 64 & 6 & 5 & - \\
\hline & 2 & 3 & 4 & 3 & & 66 & 13 & 1 & - \\
\hline & 3 & 1 & 5 & 4 & & 67 & 7 & 5 & - \\
\hline
\end{tabular}


and $-0 \cdot 05$. These values do not differ significantly from zero $\left(\chi_{\max }^{2}=2 \cdot 37\right.$ and $0 \cdot 74$ ).

The interaction structure of the population is studied in the same way as in $F$. transkaucasica, but only those nests from which at least four gynes (12 nests) or 10 workers (20 nests) are included.

The analysis of allele frequencies by the $F_{\mathrm{ST}}$ statistic suggests that about 7.7 per cent of the genic variation is between and 92.3 per cent within the nests (table 2). After a sample size correction, the values of $F_{\mathrm{ST}}$ become close to zero. Similarly, the correlation and regression estimates of genetic relatedness among gynes yield values very close to zero (table 2), suggesting that single-nest gynes are not more related to each other than to other gynes in the study area. The randomization test shows that the $b$ estimate does not differ significantly from zero $(P=0 \cdot 88)$.

The relatedness estimate among workers is considerably greater than among gynes, $b=0 \cdot 09 \pm 0 \cdot 09$, the estimate being significantly different from zero (randomization test $P=0.002$ ).

Similar results were obtained in the Vantaa population, from which 75 gynes from seven nests were examined. The allele frequencies among them were 0.32 and 0.68 (table 3 ), the expected heterozygosity thus being 0.43 . This yields a fixation index $F=0.17\left(\chi_{\max }^{2}=2 \cdot 05\right.$, ns). On the basis of $F_{\mathrm{ST}}$, 4.9 per cent of the total genic variation is due to the inter-nest component. The genotypic estimate of genetic relatedness is slightly negative, $b=$ $-0.02 \pm 0.14$, but not significantly different from zero $(P=0.75)$.

Microgeographic differentiation between nests is analysed in the Espoo population in which a greater number of nests was studied. The allele frequency distribution within the study area indicates no areal differentiation. The regression coefficient of the allele frequency difference on the metric distance between the nests does not differ significantly from zero $(t=1 \cdot 21, \mathrm{df}=188)$, and the analyses of the Gabriel connected graph indicate no departure from randomness $(t=0 \cdot 48, \mathrm{df}=\infty$, ns, and $G=3 \cdot 75$, $\mathrm{df}=5, \mathrm{~ns})$

\section{(iii) Formica polyctena}

Like $F$. aquilonia, $F$. polyctena is highly polygynous, forming large colonies living in interconnected nests. However, it is, at least in Finland, not as highly polygynous as $F$. aquilonia ( $R$. Rosengren, pers. comm.). Of the 280 gynes dissected for the present study, 80 per cent were inseminated.

The two populations of $F$. polyctena studied were almost monomorphic for the $F$ allele at the Pgi locus (table 4). Its frequency among the gynes was 0.93 in Siuntio (104 gynes from 13 nests) and 0.96 in Kauniainen (29 gynes from five nests). The allele frequencies among workers were 0.97 in Siuntio (118 workers from 15 nests) and 0.95 in Kauniainen (53 workers from eight nests), respectively.

The expected heterozygosities are 0.13 from the gyne data and 0.05 from the worker data in the Siuntio population, and 0.08 and 0.10 in Kauniainen, respectively. Due to the low frequency of the $S$ allele and the small number of nests studied, the estimates of genetic population structure (both mating and interaction structure) become rather imprecise and liable to sampling errors. The estimates of genetic relatedness among nest mates are rather high, the value of $b$ ranging from 0.19 to 0.45 (table 2). All the 
TABLE 4

Numbers of the Pgi genotypes among gynes in the nests of F. polyctena

$\begin{array}{lrrrrlrrr}\text { Nest } & & F F & F S & \text { SS } & \text { Nest } & & F F & F S \\ \text { Siuntio } & 1 & 16 & & & \text { Kauniainen } & 1 & 6 & \\ & 2 & 16 & & & & 2 & 6 & \\ & 3 & 3 & & & & 3 & 6 & \\ & 4 & 2 & 7 & & & 4 & 3 & 2 \\ & 5 & 5 & & & & 5 & 6 & \\ & 6 & 2 & 2 & 1 & & & & \\ & 7 & 5 & & & & & & \\ 8 & 8 & & & & & & \\ 9 & 8 & & & & & & \\ & 10 & 8 & & & & & & \\ 11 & 10 & & & & & & \\ 12 & 5 & 1 & & & & & \end{array}$

estimates are significantly different from zero (randomization test $P$ always $<0.005$ ), except the relatedness among gynes in Kauniainen which cannot be meaningfully tested because of the small number of heterozygotes.

\section{Discussion}

It has been suggested that inbreeding, especially in family-structured populations, might have a role in the evolution of sociality and in development of multigyne associations (Hamilton, 1964b; Michod, 1979; Breden and Wade, 1981). Inbreeding in ants could arise from intranidal mating, although with polygyny this does not indicate mating between close relatives, or from a viscous population structure with spatial differentiation within the total population. The fixation indices in the present study showed no significant deviations from panmixia, indicating that there is no significant inbreeding within the local study areas (it has to be noted that the test is not very powerful (Ward and Sing, 1970)). Intranidal mating is partly suppressed by nests producing one-sex progenies, especially in $F$. polyctena, or releasing females and males at different times (Pamilo and Rosengren, 1981).

A population of Formica ants can be divided into lower-level subgroups termed federations, colonies and families (Zakharov, 1974; see also Pamilo et al., 1978), especially in the polydomous $F$. aquilonia and $F$. polyctena. The present study gives no evidence for there being genetic subdivision within the given study areas. In this respect, the results differ from those in $F$. sanguinea, which showed extensive microdifferentiation within one population (Pamilo, 1981). Clearly, the differences in the population structures between species and populations of Formica ants are not only differences in polygyny or polydomy but also differences in genetic parameters.

The present observations indicate that all, or almost all, the gynes are inseminated, and the genotypic diversity within the worker population indicates that polygyny is functional. The data from $F$. transkaucasica and F. polyctena concur with the previous findings in Myrmecia pilosula (Craig and Crozier, 1979) and Formica sanguinea (Pamilo and Varvio-Aho, 1979; 
Pamilo, 1981) that coexistent gynes, and also workers, are genetically related to each other. This supports the interpretation that polygyny is favoured by kin selection. All the three species shared the same feature that the genetic relatedness among the gynes approximately equals that among worker nest mates, as was also found earlier in $F$. sanguinea (Pamilo, 1981). This fits the assumption that the coexistent gynes may have arisen from a single nest, although we have to remember that the estimates are average relatednesses and in reality may vary from nest to nest. The relatedness among gynes estimates the true interaction structure of the breeding population, whereas that among workers depends on the number of gynes and possible differences in their egg-laying, on the relatedness among those gynes, and on the number of males with which the gynes have mated.

The relatedness estimates of the highly polygynous $F$. aquilonia are interesting as they suggest that the nests are not genetically differentiated, i.e., single-nest gynes are not more related to each other than to average gynes within the local population. This result raises the question recognized by Williams and Williams (1957): "The crucial point is the lack of genetic relationship between conspecific queens. If this were a regular occurrence, reproductive competition between the queens would necessarily promote the loss of the sterile castes and would have to be opposed by selection at a higher level."

The problem can be approached by distinguishing between the cases when the nests split by swarming with multiple gynes and when the number of gynes increases through adoption of new fertile females. Also, the problem can be considered either from the viewpoint of the gynes or the workers.

It has been speculated that polygynous nests may react to increasing intranest genetic heterogeneity by splitting, which would help to maintain high genetic relatedness among the nest mates (Crozier, 1979; Pamilo, 1981). In such a mode of nest founding, the gynes act as a group of coequal individuals, and polygyny might be favoured either by mutualistic cooperation or by kin selection between genetically differentiated gyne groups. These alternatives are not mutually exclusive, but they do not suffice to explain the origin of polygyny.

When the gyne number increases through adoption of new females, as is the case in $F$. aquilonia and $F$. polyctena, there is an asymmetric relationship between the old and new gynes. The old gynes can be considered as donors offering an already existing nest for the recipients. The building and maintenance of a new nest, especially a big mound nest, requires significant resources in terms of worker numbers, resources that would take several years for a lone gyne to accumulate, and small and new Formica nests do not normally produce sexuals (see Brian, 1979). Further, the risk of failure for lone gynes is very great. It may therefore be far more advantageous for new gynes to join an established nest than to seek to found their own; this will result in many young gynes each year attempting to invade established nests. If we apply Wilson's (1980) model of structured demes to the present data, we find almost identical conditions for social evolution as by applying genetic relatednesses and Hamilton's (1964a) kin selection model. But by applying Wilson's alarm call model, these conditions become much less stringent (see also Johnson and Brown, 1980). More 
information on the costs and benefits of multigyne associations in different ecological conditions is needed to solve these problems.

Evolution of polygyny should not be opposed only by gyne competition but also by worker interests. If the development of the sterile caste is based on kin selection, the workers should care for a brood related to themselves. Under polygyny this condition is easily violated. The relatedness of the brood to workers can be estimated approximately by the worker-to-worker relatedness, which was positive in all the species, although rather close to zero in $F$. aquilonia as is also the relatedness of the female brood to the workers (Pamilo and Rosengren, 1981).

An alternative hypothesis to kin selection would be to consider gynes as parasites of their worker force. This approach could explain both the evolution of insect sociality in the first place (Charnov, 1978) and the evolution of polygyny (Elmes, 1973). The model of the gyne population as an entity parasitic upon, but otherwise uncontrolled by, the workers accords with the indication from our work (Pamilo and Rosengren, 1981) that the sex ratio in the Formica rufa group, including $F$, aquilonia and $F$. polyctena, is probably controlled by the gynes, whereas in many other ants there is indication for great worker effects (Trivers and Hare, 1976).

The parasitism hypothesis does not solve the problem of intergyne competition raised by Williams and Williams (1957), but there is now accumulating evidence for intergyne relatedness in several polygynous ants which serves to explain reduced competition hetween them. We can conclude that the alternative hypotheses are not mutually exclusive, and actually they may explain different aspects of the evolutionary process.

Acknowledgments. - I thank Dr R. Rosengren for providing ant material for this study, Drs R. H. Crozier, G. W. Elmes, O. Muona, R. Rosengren, and the unknown referee for critically reading the manuscript, and the National Research Council of Sciences of Finland and the Heikki and Hilma Honkanen Foundation for financial support.

\section{REFERENCES}

BREDEN, F., AND WADE, M. J. 1981. Inbreeding and evolution by kin selection. Ethol. Sociobiol., 2, 1-16.

BRIAN, M. V. 1979. Caste differentiation and division of labor. In Social Insects, vol. 1, ed. H. R. Hermann. Academic Press, New York.

BUSCHINGER, A. 1974. Monogynie und Polygynie in Insektensozietäten. In Sozialpolymorphismus bei Insekten, ed. G. H. Schmidt. Wissenschaftliche Verlagsgesellschaft, Stuttgart.

CHARNOV, E. L. 1978. Evolution of eusocial behavior: offspring choice or parental parasitism? $J$, theor. Biol., 75, 451-465.

COCKERHAM, C. C. 1973. Analysis of gene frequencies. Genetics, 74, 679-700.

CRAIG, R., AND CROZIER, R. H. 1979. Relatedness in the polygynous ant Myrmecia pilosula. Evolution, 33, 335-341.

CROZIER, R. H. 1979. Genetics of sociality. In Social Insects, vol. 1, ed. H. R. Hermann. Academic Press, New York.

DONNER, A., AND KOVAL, J. J. 1980. The estimation of intraclass correlation in the analysis of family data. Biometrics, 36, 19-25.

ELMES, G. W. 1973. Observations on the density of queens in natural colonies of Myrmica rubra L. (Hymenoptera, Formicidae). J. Animal Ecol., 42, 761-771.

GÖSSWALD, K. 1941 . Rassenstudien an der roten Waldameise Formica rufa L. auf systematischer, ökologischer, physiologischer und biologischer Grundlage. Z. Angew. Entomol., 28, 62-124.

HAMILTON, W. D. $1964 a$. The genetical evolution of social behaviour. I. J. theor. Biol., 7, 1-16. 
HAMilton, w. D. 1964b. The genetical evolution of social behaviour. II. J. theor. Biol., 7, 17-52.

hamilton, W. D. 1972. Altruism and related phenomena, mainly in social insects. Ann. Rev. Ecol. Syst., 3, 193-232.

HÖLLDOBLER, B., AND WILSON, E. O. 1977. The number of queens: an important trait in ant evolution. Naturwissenschaften, 64, 8-15.

JOHNSON, M. S., AND BROWN, J. L. 1980. Genetic variation among trait groups and apparent absence of close inbreeding in grey-crowned babblers. Behav. Ecol. Sociobiol., 7, 93-98.

LI, C. C., AND HORVITZ, D. G. 1953. Some methods of estimating the inbreeding coefficient. Am. J. Hum. Genet., 5, 107-117.

LIN, N., AND MICHENER, C. D. 1972. Evolution of sociality in insects. Quart. Rev. Biol., 47, 131-159.

MICHENER, C. D. 1964. Reproductive efficiency in relation to colony size in hymenopterous societies. Insect Soc., 11, 317-341.

MICHOD, R. 1979. Genetical aspects of kin selection: effects of inbreeding. J. theor. Biol., $81,223-233$.

MICHOD, R., AND HAMILTON, W. D. 1980. Coefficients of relatedness in sociobiology. Nature, $288,694-697$.

OSTER, G., AND WiLson, E. O. 1978. Caste and Ecology in the Social Insects. Princeton University Press, Princeton, N.J.

PAMILO, P. 1981. Genetic organization of Formica sanguinea populations. Behav. Ecol. Sociobiol, , 9, 45-50.

PAMILO, P., AND CROZIER, R. H. 1981. Measuring genetic relatedness in natural populations: methodology. Theor. Pop. Biol, in press.

PAMILO, P., AND ROSENGREN, R. 1981. Sex ratio strategies in Formica ants. Unpubl. manuscript.

PAMILO, P., ROSENGREN, R., VEPSÄLÄINEN, K., VARVIO-AHO, S., AND PISARSKI, B. 1978. Population genetics of Formica ants. I. Patterns of enzyme gene variation. Hereditas, 89, 233-248.

PAMILO, P., AND VARVIO-AHO, S. 1979. Genetic structure of nests in the ant Formica sanguinea. Behav. Ecol. Sociobiol., 6, 91-98.

RICHARDS, O. W., AND RICHARDS, M. J. 1951. Observations on the social wasps of South America (Hymenoptera: Vespidae). Trans. R. Entomol. Soc. London, 102, 1-170.

ROSENGREN, R. 1969. Notes regarding the growth of a polycalic nest system in Formica uralensis Ruzsky. Notul. Entomol., 49, 211-230.

ROSENGREN, R. 1971. Route fidelity, visual memory and recruitment behaviour in foraging wood ants of the genus Formica (Hymenoptera, Formicidae). Acta Zool. Fenn., 133, $1-106$.

ROYALTEY, H. H., ASTRACHAN, E., AND SOKAL, R. R. 1975. Tests for patterns in geographic variation. Geograph. Anal., 7, 369-395.

SCHMIDT, G. H. 1972. Männchendetermination in polygynen Waldameisenstaat. Zool. Anz., $189,159-169$.

STURTEVANT, A. H. 1938. Essays on evolution. II. On the effects of selection on social insects. Quart. Rev. Biol., 13, 74-76.

TRIVERS, R. L., AND HARE, H. 1976. Haplodiploidy and the evolution of the social insects. Science, 191, 249-263.

VAR VIO-AHO, S., AND PAMILO, P. 1980. A new buffer system with wide applicability. Isozyme Bull., 13, 114.

WADE, M. J. 1980. An experimental study of kin selection. Evolution, 34, 844-855.

WARD, R. H., AND SING, C. F. 1970. A consideration of the power of the $\chi^{2}$ test to detect inbreeding effects in natural populations. Am. Nat., 104, 355-365.

WILLIAMS, G. C., AND WILLIAMS, D. C. 1957. Natural selection of individually harmful social adaptations among sibs with special reference to social insects. Evolution, 11, 32-39.

WILSON, D. S. 1980. The Natural Selection of Populations \& Communities. The Benjamin/Cummings Publ. Co., Menlo Park, California.

WRIGHT, S. 1943. Isolation by distance. Genetics, 28, 114-138.

ZAKHAROV, A. A. 1974. Structure and formation of the colony in ants Formica s.str. (Hymenoptera, Formicidae) (in Russian with English summary). Zool. Zhurn., 53, 58-65. 